\title{
Penerapan Metode Pembelajaran IPS Berbasis Pendekatan Saintifik Dalam Mengintegrasikan Karakter Bangsa di SMPN Kecamatan Sape
}

\author{
Ida Waluyati ${ }^{1}$ Irfan $^{2}$ \\ Program Studi Pendidikan Sosiologi,STKIPBima.Jalan PiereTendeanKel. MandeTel.Fax(0374) \\ 42801, Bima 84191, Indonesia. \\ Email: irfanfagih@gmail.com
}

\begin{abstract}
ABSTRAK
Penelitian ini bertujuan untuk mendeskripsikan penerapan metode pembelajaran IPS berbasis pendekatan saintifik dalam mengintegrasikan karakter bangsa di SMPN Kecamatan Sape, Bima. Penelitian ini menggunakan pendekatan deskriptif kualitatif. Teknik analisis data menggunakan reduksi, penyajian, verifikasi. Hasil penelitian menunjukkan bahwa integrasi nilai karakter bangsa berbasis pendekatan saintifik melalui penerapan metode pembelajaran IPS SMPN di Kecamatan Sape, Bima dilaksanakan sesuai penerapan sintaks metode pembelajaran.
\end{abstract}

Kata Kunci : Karakter Bangsa, Pendekatan Saintifik, Metode Pembelajaran, IPS

The Implementation of Learning Methods of Social Studies Based on The Scientific Approach in Integrating The Nation Characters

The research aims to describe the implementation of learning methods of social studies based on the scientific approach in integrating the nation characters at SMPN in Sape Regions, Bima. The study uses the descriptive qualitative approach. The technical analysis data that are used: reduction, presentation, verification. The result of the research shows that the implementation of learning methods of social studies based on the scientific approach in integrating the nation characters at SMPN Sape, Bima, that is implemented in the teaching stage that is suitable with the used sintax of methods.

Keywords : Nation Characters, Scientific Approach, Learning Methods, Social Studies 


\section{PENDAHULUAN}

Penumbuhan budi pekerti secara terintegrasi dalam pembelajaran dilakukan selama proses pembelajaran berlangsung baik didalam maupun di luar kelas. Selama proses pembelajaran, siswa berinteraksi dengan bahan ajar, guru, dan antar siswa melalui berbagai aktivitas belajar. Melalui interaksi dengan substansi bahan ajar, siswa memperoleh pengetahuan tentang nilai (moral knowing). Sementara itu, melalui interaksinya dengan guru dan sesama siswa dalam berbagai kegiatan pembelajaran, para siswa akan memperoleh tentang nilai-nilai moral yang baik lebih mendalam dan meresapi pentingnya nilai-nilai moral (moral feeling) serta tumbuh perilaku sehari-hari yang dilandasi oleh nilainilai budi pekerti yang baik tersebut (moral action). Berdasarkan data statistik dari Unit Pelaksana Tugas Pendidikan, Kebudayaan, Pemuda dan Olahraga Kecamatan Sape, Kabupaten Bima bahwa terdapat enam SMP Negeri yang telah melaksanakan Kurikulum 2013 sejak tahun pelajaran 2017/2018, yaitu SMPN 2 Sape, SMPN 3 Sape, SMPN 4 Sape, SMPN 6 Sape, SMPN 7 Sape, serta SMPN 8 Sape. Sedangkan SMPN 1 Sape dan SMPN 5 Sape telah lebih awal merintis dalam pelaksanakan Kurikulum 2013, yakni sejak tahun pelajaran 2016/2017. Penelitian ini hanya difokuskan pada dua sekolah, yakni SMPN 1 Sape dan SMPN 5 Sape dengan pertimbangan bahwa kedua sekolah ini dinilai sudah dua tahun berjalan melaksanakan Kurikulum 2013 yaitu kelas VII dan VIII dibandingkan dengan keenam sekolah lainnya yang baru satu tahun dalam pelaksanaan Kurikulum 2013. Hasil wawancara dengan Kepala Sekolah dan guru IPS pada kedua SMPN tersebut bahwa sejak tahun 2017 terdapat berbagai permasalahan yang berkaitan dengan sikap dan perilaku peserta didik yang tidak mencerminkan nilai-nilai karakter dalam pembelajaran IPS. Hal tersebut dibuktikan dengan adanya berbagai pengaduan yang ditujukan kepada pihak sekolah, antara lain, siswa kurang mampu bekerjasama, siswa tidak disiplin pada saat pembelajaran IPS, kurangnya motivasi belajar, siswa membawa senjata tajam, dan bahkan siswa tidak saling menghargai dalam kelas. Gagasan utama dalam mengatasi masalah tersebut adalah penggunaan pendekatan saintifik dalam proses pembelajaran IPS tingkat SMP diperlukan sebagai pendekatan dalam mengintegrasikan nilai-nilai karakter pada peserta didik di tengah krisis moral yang terjadi di abad ke-21 sebagaimana amanat kurikulum 2013. Pembelajaran IPS sebagai mata pelajaran yang diberikan pada kurikulum Sekolah Dasar dan Menengah memiliki peran penting dalam pembentukan karakter bangsa sebab melalui pembelajaran IPS, peserta didik diajarkan untuk menjadi warga negara Indonesia yang baik dan penuh kedamaian.

Urgensi penelitian ini adalah diharapkan dapat memberi kontribusi bagi guru mata pelajaran IPS di tingkat SMP Negeri yang ada di Kecamatan Sape, Kabupaten Bima untuk dapat secara aktif menerapkan pendekatan saintifik pada proses pembelajaran IPS melalui penerapan berbagai metode yang bervariatif, sehingga nilai-nilai karakter sesuai budaya bangsa dapat terinternalisasi secara dini.

Definisi karakter menurut Lickona (1992:51) dapat dijelaskan sebagai Character as "a reliable inner disposition to respond to situations in a morally good way. Character so conceived has three interrelated parts: moral knowing, moral feeling, and moral behavior". Lebih lanjut, Panduan Pusat Kurikulum dan Perbukuan Kementerian Pendidikan dan Kebudayaan (2015:8) menjelaskan karakter bangsa sebagai kualitas perilaku kolektif kebangsaan yang khas-baik yang tercermin dalam kesadaran, pemahaman, rasa, karsa, dan perilaku berbangsa dan bernegara sebagai hasil olah pikir, olah hati, olah rasa dan karsa, serta olah raga seseorang atau sekelompok orang.

Berdasarkan Panduan Pusat Kurikulum dan Perbukuan Kementerian Pendidikan dan Kebudayaan (2015:10), tujuan pendidikan karakter adalah mengembangkan nilai-nilai yang membentuk karakter, meliputi: (1) mengembangkan potensi peserta didik agar menjadi manusia berhati baik, berpikiran baik, dan berperilaku baik, (2) membangun bangsa yang berkarakter Pancasila, (3) mengembangkan potensi warga negara agar memiliki sikap percaya diri, bangga pada bangsa dan negaranya serta mencintai umat manusia. Nilai-Nilai Karakter tersebut meliputi, religius, jujur, toleransi, disiplin, kerja keras, kreatif, mandiri, demokratis, rasa ingin tahu, semangat kebangsaan, cinta tanah air, menghargai persahabatan, bersahabat/komunikatif, cinta damai, gemar membaca, peduli lingkungan, 
peduli sosial, serta tanggung jawab. Prinsip dan Pendekatan Pengembangan Pendidikan Budaya dan Karakter Melalui Pembelajaran yakni (1) Berkelanjutan yaitu proses pengembangan nilainilai budaya dan karakter bangsa merupakan sebuah proses panjang, dimulai dari awal peserta didik masuk sampai selesai dari suatu satuan pendidikan, (2) Melalui semua mata pelajaran, pengembangan diri, dan budaya sekolah yaitu proses pengembangan nilai-nilai budaya dan karakter bangsa dilakukan melalui setiap mata pelajaran dan setiap kegiatan kurikuler dan ekstrakurikuler, (3) Nilai tidak diajarkan tapi dikembangkan yaitu materi nilai budaya dan karakter bangsa bukanlah bahan ajar biasa artinya nilai-nilai itu tidak dijadikan pokok bahasan yang dikemukakan seperti halnya ketika mengajarkan suatu konsep, teori, prosedur, ataupun fakta seperti dalam berbagai mata pelajaran, (4) Proses pendidikan dilakukan peserta didik secara aktif dan menyenangkan yaitu proses pendidikan nilai budaya dan karakter bangsa dilakukan oleh peserta didik bukan oleh guru.

Berdasarkan definisi Pendekatan Saintifik menurut L.R. Gay, Geoffrey E.Mills; dan Peter Airasian (2012:6) bahwa dalam konteks pembelajaran, pendekatan saintifik sangat penting digunakan untuk mengembangkan cara-cara berpikir dan bekerja secara ilmiah. Pendekatan saintifik dalam pembelajaran didasarkan pada proses keilmuan yang terdiri dari merumuskan data, dan menarik simpulan. Konsep dasar mengenai proses pembelajaran menurut pendekatan saintifik yaitu bahwa peserta didik dipandang sebagai subjek yang memiliki kemampuan untuk secara aktif mencari, mengolah, mengkonstruksi, dan menggunakan pengetahuan. Lebih lanjut, dalam Permendikbud No 103 Tahun 2014 Tentang Pembelajaran, dinyatakan bahwa pembelajaran dengan pendekatan saintifik terdiri atas lima langkah kegiatan belajar yakni: (a) Mengamati yakni peserta didik menggunakan panca inderanya untuk mengamati fenomena yang relevan dengan apa yang dipelajari, (b) Menanya yakni peserta didik merumuskan pertanyaan tentang apa yang tidak diketahui atau belum dapat dilakukan terkait dengan fenomena yang diamati, (c) Mengumpulkan informasi yakni peserta didik mengumpulkan data melalui berbagai teknik, misalnya melalukan eksperimen, mengamati obyek, wawancara dengan narasumber, membaca buku, dan sumber lain, (d) Menalar/mengasosiasi, yakni peserta didik menggunakan data atau informasi yang sudah dikumpulkan untuk menjawab pertanyaanpertanyaan yang dirumuskan, (e) Mengomunikasikan yakni peserta didik menyampaikan jawaban terhadap pertanyaanpertanyaan ke kelas secara lisan, tertulis atau media lain.

Barth (1990:28) mendefinisikan IPS sebagai: "Social studies is the interdisciplinary integration of social sciences and humanities concepts for the purpose of practicing citizenship skills on critical social issues". IPS menekankan pada aspek integrasi yang berupaya menyatukan konsep-konsep ilmu sosial dalam tema pembelajarannya.

Tujuan Ilmu Pengetahuan Sosial menurut Skeel (1995:11) yaitu "The function of social studies should be to assist children in development of a good self-concept; help them recognize and appreciate the global society and its multicultural composition; further the socialization process-social, economic, and political; provide knowledge of the past and present as basis for decosion making; develop problem-solving and valuing skills; and foster an active participant role in society".

Berdasarkan pandangan tersebut, tujuan utama IPS adalah untuk mengembangkan konsep dan potensi peserta didik agar mengenal dan peka terhadap masalah sosial yang terjadi di masyarakat.

Tujuan penelitian adalah untuk mendeskripsikan integrasi nilai-nilai karakter berbasis pendekatan saintifik melalui penerapan metode dalam proses pembelajaran IPS pada SMP Negeri di Kecamatan Sape, Kabupaten Bima.

\section{METODE PENELITIAN}

Penelitian ini menggunakan pendekatan deskriptif kualitatif untuk mendeskripsikan secara mendalam pengintegrasian nilai-nilai karakter berbasis pendekatan saintifik melalui penerapan metode pembelajaran IPS. Subyek penelitian ini adalah 3 orang guru IPS SMPN 1 Sape, 3 orang guru IPS SMPN 5 Sape, serta siswa kelas VII dan VIII yang mengikuti pembelajaran IPS pada SMPN 1 Sape dan SMPN 5 Sape yang berjumlah 24 siswa dengan mengambil 2 orang responden dari setiap kelas. 
Variabel penelitian adalah: (1) Nilainilai karakter meliputi indikator: religius, jujur, toleransi, disiplin, kerja keras, kreatif, mandiri, demokratis, rasa ingin tahu, semangat kebangsaan, cinta tanah air, menghargai persahabatan, bersahabat/komunikatif, cinta damai, gemar membaca, peduli lingkungan, peduli sosial, serta tanggung jawab, (2) Pendekatan saintifik meliputi indikator: (a) Mengamati yakni peserta didik menggunakan panca inderanya untuk mengamati fenomena yang relevan dengan apa yang dipelajari, (b) Menanya yakni peserta didik merumuskan pertanyaan tentang apa yang tidak diketahui, (c) Mengumpulkan informasi yakni peserta didik mengumpulkan data melalui berbagai teknik, (d) Menalar/mengasosiasi, yakni peserta didik menggunakan data atau informasi yang sudah dikumpulkan untuk menjawab pertanyaan-pertanyaan yang dirumuskan, (e) Mengomunikasikan yakni peserta didik menyampaikan jawaban terhadap pertanyaanpertanyaan ke kelas secara lisan, tertulis atau media lain. (3) Metode Pembelajaran IPS meliputi metode discovery learning/inkuiri, cooperatif learning, problem solving.

Teknik pengumpulan data berupa (1) Wawancara terhadap guru bidang studi IPS dan siswa kelas VII dan VIII, (2) Observasi kgiatan pembelajaran IPS, (3) Dokumentasi berupa perangkat pembelajaran guru IPS berupa, RPP.

Teknik analisis data meliputi tahap reduksi (penyerderhanaan data), tahap display (penyajian data), serta verifikasi (kesimpulan data). Selanjutnya untuk menguji keabsahan data dilakukan teknik trianggulasi sumber dan teknik.

\section{HASIL DAN PEMBAHASAN}

Proses pembelajaran pada Pendidikan Dasar dan Menengah diatur melalui Peraturan Menteri Pendidikan dan Kebudayaan Nomor 103 Tahun 2014 yang dipayungi dengan Peraturan Menteri Pendidikan dan Kebudayaan Nomor 22 Tahun 2016 tentang Standar Proses beserta lampirannya. Dalam lampiran Peraturan Menteri tersebut dinyatakan tentang konsep dasar mengenai proses pembelajaran yaitu bahwa peserta didik dipandang sebagai subjek yang memiliki kemampuan untuk secara aktif mencari, mengolah, mengkonstruksi, dan menggunakan pengetahuan. Sejalan dengan pandangan tersebut, pembelajaran harus berkenan dengan kesempatan yang diberikan kepada peserta didik untuk mengkonstruksi pengetahuan dalam proses kognitifnya.

Pada tahap implementasi dikembangkan pengalaman belajar dan proses pembelajaran yang bermuara pada pembentukan karakter dalam diri individu peserta didik. Proses ini dilaksanakan melalui proses pembudayaan dan pemberdayaan sebagaimana digariskan sebagai salah satu prinsip penyelenggaraan pendidikan nasional.

Sejalan dengan konsep dasar dan prinsipprinsip pembelajaran tersebut, pembelajaran pada Kurikulum 2013 menggunakan pendekatan saintifik atau pendekatan berbasis proses keilmuan. Dalam Permendikbud No.

103 Tahun 2014 dinyatakan bahwa pembelajaran dengan pendekatan saintifik terdiri atas lima langkah kegiatan belajar yakni mengamati (observing), menanya (questioning), mengumpulkan informasi/mencoba (experimenting), menalar atau mengasosiasi (associating), mengomunikasikan (communicating) yang dapat dilanjutkan dengan mencipta.

Hasil penelitian ini juga relevan dengan hasil penelitian sebelumnya (Sri Wandan Sari Ningsih, 2017: 128-132) yang berjudul Implementasi Pendidikan Karakter Pada Mata Pelajaran IPS menunjukkan bahwa implementasi pendidikan karakter pada mata pelajaran IPS perlu didukung melalui proses pembelajaran yang kontekstual dan terpadu dan didesain melalui rancangan RPP yang berkarakter.

Proses pembelajaran IPS di dalam dan luar kelas pada SMPN di Kecamatan Sape, Bima meliputi kegiatan pendahuluan, inti, dan penutup. Sebagian atau seluruh kegiatan pembelajaran dipilih dan dilaksanakan agar peserta didik memperoleh pengetahuan tentang nilai, memahami atau meresapi pentingnya nilai, dan mempraktikkan nilai-nilai karakter. Berikut disajikan integrasi nilai karakter melalui penerapan beberapa metode pembelajaran IPS SMPN di Kecamatan Sape, Bima yakni:

1. Integrasi Nilai-Nilai Karakter pada Metode Discovery Learning/Inkuiri

Menurut Permendikbud Nomor 22 Tahun 2016 bahwa untuk memperkuat pendekatan ilmiah (saintifik), tematik terpadu perlu ditetapkan pembelajaran berbasis penyingkapan penelitian (discovery learning). Metode discovery dipandang sebagai catatn 
pengingat bagi guru untuk selalu meningkatkan keterlibatan siswa dalam menemukan sesuatu dan membantu siswa berpikir secara analitis, berani dan kreatif berimajinasi serta menarik simpulan ilmiah berdasarkan pengamatan atas fakta-fakta dan kesimpulan yang diperoleh. Metode discovery ini juga dapat membelajarkan sikap tertutama untuk memfasilitasi pemerolehan moral knowing. Berdasarkn hasil observasi dan wawancara terhadap guru IPS dan siswa bahwa dalam praktik discovery learning, siswa diberi lebih banyak kesempatan bagi keterlibatan dan inisiatif dalam melakukan penyelidikan. Guru lebih memberi kesempatan siswa menjawab pertanyaan sendiri atau menjaring pertanyaan siswa untuk didiskusikan lebih lanjut dan ditanggapi oleh siswa yang lain secara keseluruhan pada akhir kegiatan. Dalam proses ini, guru mendorong siswa yang bertanya untuk mendiskusikan pertanyaan siswa dengan teman sekelas dan merumuskan kemungkinan tanggapan atau memberi tugas tambahan yang mengarahkan siswa untuk mendapat jawaban dari referensi yang tersedia. Guru juga membimbing siswa dalam mencari sumber, melakukan penemuan dan untuk menarik kesimpulan. Adapun penumbuhan nilai karakter pada metode discovery learning pada pembelajaran IPS SMPN di Kecamatan Sape, Bima dapat dijelaskan pada Tabel 1 berikut.

Tabel 1. Integrasi Nilai-Nilai Karakter Melalui Metode Discovery Learning Pada Pembelajaran IPS SMPN di Kecamatan Sape, Bima

\begin{tabular}{|c|c|c|c|}
\hline No & Sintaks Metode & $\begin{array}{c}\text { Deskripsi Kegiatan } \\
\text { Pembelajaran }\end{array}$ & $\begin{array}{c}\text { Nilai Karakter Yang } \\
\text { Ditumbuhkembangkan }\end{array}$ \\
\hline 1. & $\begin{array}{l}\text { Merumuskan } \\
\text { Pertanyaan }\end{array}$ & $\begin{array}{l}\text { Siswa merumuskan } \\
\text { pertanyaan, masalah atau } \\
\text { topik yang akan diselidiki. }\end{array}$ & $\begin{array}{l}\text { Berpikir kritis, } \\
\text { komunikasi, rasa ingin } \\
\text { tahu }\end{array}$ \\
\hline 2. & Merencanakan & $\begin{array}{l}\text { Siswa merencanakan } \\
\text { prosedur pengumpulan dan } \\
\text { analisis data. }\end{array}$ & $\begin{array}{l}\text { Kreatif, disiplin, kritis, } \\
\text { kerjasama }\end{array}$ \\
\hline 3. & $\begin{array}{l}\text { Mengumpulkan } \\
\text { dan menganalisi } \\
\text { data }\end{array}$ & $\begin{array}{l}\text { Siswa mengumpulkan fakta } \\
\text { atau data yang diperlukan } \\
\text { serta menganalisis data/hasil }\end{array}$ & $\begin{array}{l}\text { Kreatif, tanggungjawab, } \\
\text { kerja keras, kerjasama }\end{array}$ \\
\hline 4. & $\begin{array}{l}\text { Menarik } \\
\text { kesimpulan }\end{array}$ & $\begin{array}{l}\text { Siswa menarik } \\
\text { simpulan/penjelasan ringkas }\end{array}$ & Komunikasi, kerjasama \\
\hline 5. & $\begin{array}{l}\text { Penerapan dan } \\
\text { Tindak Lanjut }\end{array}$ & $\begin{array}{l}\text { Siswa menerapkan hasil dan } \\
\text { mengeksplorasi pertanyaan- } \\
\text { pertanyaan lanjutan untuk } \\
\text { dicari jawabannya }\end{array}$ & $\begin{array}{l}\text { Kritis, kerjasama, } \\
\text { kreatif, komunikasi }\end{array}$ \\
\hline
\end{tabular}


2. Integrasi Nilai-Nilai Karakter pada Metode Problem Based Learning

Pembelajaran berbasis masalah menjadikan masalah sebagai titik sentral kajian dalam proses pembelajaran serta dikaji untuk ditemukan pemecahannya. Masalah yang dijadikan kajian dalam pembelajaran adalah berupa masalah nyata, kontekstual relevan dengan yang ada dilingkungan kehidupan seharihari siswa. Berdasarkan hasil observasi dan wawancara dengan guru IPS dan siswa, bahwa dalam penerapan metode ini, guru memfasilitasi siswa terkait permasalahan nyata yang ditemukan dengan menggunakan Lembar Kerja yang telah disiapkan guru. Guru melakukan intervensi terhadap siswa yang belum terbiasa dalam pembelajaran berbasisi masalah untuk menghindari kesulitan yang dihadapi siswa. Adapun penumbuhan nilai-nilai karakter pada metode discovery learning/inkuri dapat dijelaskan pada Tabel 2 berikut.

Tabel 2. Integrasi Nilai-Nilai Karakter Melalui Metode Problem-Based Learning Pada Pembelajaran IPS SMPN di Kecamatan Sape, Bima

\begin{tabular}{|c|c|c|c|}
\hline No & Sintaks Metode & $\begin{array}{c}\text { Deskripsi Kegiatan } \\
\text { Pembelajaran }\end{array}$ & $\begin{array}{c}\text { Nilai Karakter Yang } \\
\text { Ditumbuhkembangkan }\end{array}$ \\
\hline 1. & $\begin{array}{l}\text { Klarifikasi } \\
\text { Permasalahan }\end{array}$ & $\begin{array}{l}\text { Siswa melakukan } \\
\text { identifikasi dan klarifikasi } \\
\text { terhadap masalah yang } \\
\text { ditemukan }\end{array}$ & $\begin{array}{l}\text { Berpikir kritis, } \\
\text { komunikasi, rasa ingin } \\
\text { tahu }\end{array}$ \\
\hline 2. & Brainstorming & $\begin{array}{l}\text { Siswa melakukan } \\
\text { brainstorming masalah dan } \\
\text { mengembangkan alternatif } \\
\text { peyelesaian masalah dengan } \\
\text { fasilitasi guru. }\end{array}$ & $\begin{array}{l}\text { Kreatif, disiplin, kritis, } \\
\text { kerjasama }\end{array}$ \\
\hline 3. & $\begin{array}{l}\text { Pengupulan } \\
\text { informasi dan data }\end{array}$ & $\begin{array}{l}\text { Siswa mengumpulkan dan } \\
\text { mengolah fakta atau data } \\
\text { terkait penyelesaian masalah } \\
\text { melalui berbagai sumber }\end{array}$ & $\begin{array}{l}\text { Keatif, tanggungjawab, } \\
\text { kerja keras, kerjasama }\end{array}$ \\
\hline 4. & $\begin{array}{l}\text { Berbagi informasi } \\
\text { dan berdiskusi } \\
\text { untuk menemukan } \\
\text { solusi penyelesaian } \\
\text { masalah }\end{array}$ & $\begin{array}{l}\text { Siswa menarik } \\
\text { simpulan/penjelasan ringkas }\end{array}$ & Komunikasi, kerjasama \\
\hline 5. & $\begin{array}{l}\text { Presentasi hasil } \\
\text { penyelesaian } \\
\text { masalah }\end{array}$ & $\begin{array}{l}\text { Siswa mempresentasikan } \\
\text { hasil brainstorming dan } \\
\text { melakukan perbaikan hasil } \\
\text { diskusi terkait penyelesaian } \\
\text { masalah }\end{array}$ & $\begin{array}{l}\text { Kritis, kerjasama, } \\
\text { kreatif, komunikasi }\end{array}$ \\
\hline
\end{tabular}

3. Integrasi Nilai-Nilai Karakter pada Metode Cooperatif Learning

Dalam pembelajaran kooperatif, siswa berlatih berbagai keterampilan sosial sesuai dengan tuntutan kempetensi pada Kurikulum 2013 yaitu kompetensi sikap sosial, spiritual, pengetahuna dan keterampilan. berdasarkan hasil observasi dan wawancara terhadap guru IPS dan siswa pada SMPN 5 Sape dan SMPN 1 Sape bahwa dalam pembelajaran, siswa diberi Lembar
Kegiatan (LK) yang dapat berisi pertanyaan atau tugas yang direncanakan sesuai Indikator Pencapaian Kompetensi. Selama kerja kelompok berlangsung, tugas anggota kelompok adalah mencapai ketuntasan materi yang disajikan guru dan saling membantu teman sekelompok mencapai ketuntasan materi. Adapun penumbuhan nilai-nilai karakter pada metode Cooperatif learning dapat dijelaskan pada Tabel 3 berikut. 
Tabel 3. Integrasi Nilai-Nilai Karakter Melalui Metode Cooperatif Learning Pada Pembelajaran IPS SMPN di Kecamatan Sape, Bima

\begin{tabular}{|c|c|c|c|}
\hline No & Sintaks Metode & $\begin{array}{c}\text { Deskripsi Kegiatan } \\
\text { Pembelajaran }\end{array}$ & $\begin{array}{c}\text { Nilai Karakter Yang } \\
\text { Ditumbuhkembangkan }\end{array}$ \\
\hline 1. & $\begin{array}{l}\text { Menyampaikan } \\
\text { Tujuan dan } \\
\text { memotivasi siswa }\end{array}$ & $\begin{array}{l}\text { Guru menyampaikan tujuan } \\
\text { pembelajaran, manfaat } \\
\text { materi dan apersepsi }\end{array}$ & $\begin{array}{l}\text { motivasi, rasa ingin } \\
\text { tahu }\end{array}$ \\
\hline 2. & $\begin{array}{l}\text { Menyajikan } \\
\text { informasi }\end{array}$ & $\begin{array}{l}\text { Guru menyampaikan materi } \\
\text { kepada siswa secara verbal, } \\
\text { demonstrasi atau bahan } \\
\text { bacaan. }\end{array}$ & $\begin{array}{l}\text { Kreatif, kritis, rasa ingin } \\
\text { tahu }\end{array}$ \\
\hline 3. & $\begin{array}{l}\text { Mengorganisasikan } \\
\text { siswa ke dalam } \\
\text { kelompok- } \\
\text { kelompok belajar }\end{array}$ & $\begin{array}{l}\text { Guru membentuk kelompok } \\
\text { belajar dan membantu tiap } \\
\text { kelompok agar melakukan } \\
\text { transisi secara efisien, }\end{array}$ & $\begin{array}{l}\text { Keatif, tanggungjawab, } \\
\text { kerja keras, kerjasama }\end{array}$ \\
\hline 4. & $\begin{array}{l}\text { Membimbing } \\
\text { kelompok bekerja } \\
\text { dan belajar }\end{array}$ & $\begin{array}{l}\text { Guru mendampingi } \\
\text { kelompok belajar }\end{array}$ & $\begin{array}{l}\text { Komunikasi, kerjasama, } \\
\text { tanggungjawab }\end{array}$ \\
\hline 5. & $\begin{array}{l}\text { Melakukan } \\
\text { evaluasi }\end{array}$ & $\begin{array}{l}\text { Guru melakukan evaluasi } \\
\text { terhadap materi yang telah } \\
\text { dipelajari atau meminta } \\
\text { masing-masing kelompok } \\
\text { mempresentasikan hasil } \\
\text { kerjanya }\end{array}$ & $\begin{array}{l}\text { Kritis, kerjasama, } \\
\text { kreatif, komunikasi, } \\
\text { tanggungjawab }\end{array}$ \\
\hline 6. & $\begin{array}{l}\text { Memberikan } \\
\text { penghargaan }\end{array}$ & $\begin{array}{l}\text { Guru memberi penghargaan } \\
\text { terhadap prestasi individu } \\
\text { maupun kelompok }\end{array}$ & $\begin{array}{l}\text { Saling menghargai, } \\
\text { motivasi }\end{array}$ \\
\hline
\end{tabular}




\section{KESIMPULAN}

Integrasi karakter bangsa berbasis pendekatan saintifik melalui penerapan metode pembelajaran IPS SMPN di Kecamatan Sape, Bima sudah dilaksanakan sesuai sintaks metode yang digunakan. Penggunaan metode discovery learning, cooperatif learning, serta problem solving sering dipakai oleh guru dalam pembelajaran IPS sebagai wadah memfasilitasi peserta didik dalam pengembangan karakter bangsa pada diri siswa.

\section{SARAN}

Mengingat penelitian ini banyak keterbatasan, diharapkan kepada peneliti berikutnya agar lebih mengembangkan penelitian eksperimen metode pembelajaran yang dapat menjawab persoalan karakter siswa pada SMPN di Kecamatan Sape, Bima.

Ucapan terima kasih kepada pihak KEMENRISTEKDIKTI sebagai sumber pendanaan penelitian melalui Program Hibah Penelitian Kategori Kompetitif Nasional 2019. Ucapan terima kasih juga pada seluruh responden di SMPN 1 dan SMPN 5 Sape, Kabupaten Bima, NTB atas kontributif besar atas penelitian ini serta kepada para Reviewer Nasional atas segala masukan dan kritikan yang berharga dalam penyempurnaan penelitian ini.

\section{DAFTAR PUSTAKA}

Barth, James, L. (1990). Methods of instruction in social studies education. Lanham: University Press of America.

Ellis, Arthur, K. (1997). Teaching and learning elementary social studies. United States: A Viacom Company.

Gay, L.R., Mills G., \& Airasian P. (2012). Educational Research: Competencies for Analysis and Applications, 10th ed. Boston: Pearson. Kemendikbud. 2015. Pusat Kurikulum dan Perbukuan.

Lickona, T. (1992). Educating for character, how our schools can teach respect, respect and responsibility. New York: Bantam Books

Massialas, G. Byron \& Allen, F. Rodney. (1996). Critical issues in teaching social studies K-12. United States: Wadsworth Publishing Company.

Hanang AR Rasyid. (2016). Implementasi Pendidikan Karakte dalam Pembelajaran IPS di Madrasah Aliyah. Jurnal Ilmu-Ilmu Sosial-Universitas Negeri Yogyakarta, 15 (1), 3-4.

Irfan, I. (2017). Analisis Praktik Perjudian Dalam Pilkades (Studi Pada Lima Desa Dua Kecamatan Di Kabupaten Bima). Jurnal Pendidikan IPS, 7(2), 7383.

Irfan, I., \& Mukminah, M. (2016). Upacara Khitanan Sebagai Media Perekat Sosial (Studi Di Desa Sangia Kecamatan Sape Kabupaten Bima). Jurnal Pendidikan IPS, 6(2).

Kemendikbud. (2016). Panduan Pembelajaran Untuk Sekolah Menengah Pertama. Jakarta. 